\title{
Systematic reviews on preventing fall-related injuries in older people
}

Falls are a common cause of injury in older people. Injuries caused by falls, such as broken bones or head injury, may result in disability, premature death, or a lower quality of life. Three systematic reviews currently published in the Cochrane Database of Systematic Reviews evaluate the effectiveness of interventions for preventing falls and fall-related injuries in older adults. ${ }^{1-3}$ One of these reviews ${ }^{1}$ has recently been updated and the findings are presented below. The other two reviews are currently being updated, and are expected to be published later in 2008. One of these reviews ${ }^{2}$ has been divided into two, and the new protocols have been published. ${ }^{45}$

\section{POPULATION-BASED INTERVENTIONS FOR THE PREVENTION OF FALL-RELATED INJURIES IN OLDER PEOPLE}

This review ${ }^{1}$ included studies with population-based interventions, which are defined as interventions that may target an individual (wearing a hip protector, improving balance, and lower limb strength) or the environment (installing hand rails, laying carpeting).

According to the review authors, the essential element of population-based approaches is the embedding of successful countermeasures (eg, hip protectors, environmental modifications) into multistrategy programs that integrate into existing social structures and networks. The success of these programs thus relies not on the effectiveness of the specific countermeasures per se, but on the mechanism for ensuring their uptake by members of the target subpopulation.

Prospective controlled community trials were included in this Cochrane review. None was randomized. The unit of analysis in each trial was the entire community, but the target study populations were people aged 60 years and over. Outcomes were the incidence of fallrelated injuries before and after the intervention and the change in the incidence before and after intervention compared with a control (no intervention) group.
Incidence of injury was counted as treatment from a medical practitioner.

Six studies ${ }^{6-11}$ were included in the review and described population-based interventions conducted in Australia, Denmark, Norway, Sweden, and Taiwan. Half of the studies were based on the World Health Organization (WHO) safe communities model of safety and injury prevention. ${ }^{12}$ The model was developed in Sweden before its adoption by $\mathrm{WHO}$, and the three communities receiving the intervention were designated WHO safe communities.

Five studies had similar study designs. These studies used multifaceted interventions which included a combination of educational advice, home visits, promotion of physical activity, home hazard reduction, and training for council services personnel, healthcare workers, and public space and housing planners. The sixth study ${ }^{8}$ examined the effect of one intervention, group tai chi exercises, on the incidence of injurious falls in older people in rural villages in Taiwan.

All six studies found an overall reduction in fall-related injuries among members of the intervention populations. For three studies a reduction in injuries was statistically significant at the $95 \%$ confidence level for some subpopulations. The relative reduction in fall-related injuries across the six studies ranged from $6 \%$ to $33 \%$.

On the basis of the findings of the included studies, the review authors concluded that population-level interventions can reduce the incidence of fall-related injuries in older populations. The full review can be found on the Cochrane Database of Systematic Reviews.

The Cochrane Database of Systematic Reviews contains over 3000 intervention reviews and is available at www. thecochranelibrary.com.

The main review highlighted in this article $^{1}$ is registered to the Cochrane Injuries Group (www.injuries.cochrane. org). The other reviews mentioned ${ }^{2}{ }^{3}$ are registered to the Cochrane Bone, Joint and Muscle Trauma Group (www.bjmtg. cochrane.org). The work of both groups involves preparing, maintaining, and promoting the accessibility of systematic reviews on different aspects of the prevention, treatment, and rehabilitation of injury. People interested in contributing to this work can contact me, the Review Group Coordinator of the Injuries Group, at emma.sydenham@1shtm.ac.uk, or Lindsey Elstub, the Review Group Coordinator of the Bone, Joint and Muscle Trauma Group at lindsey. elstub@manchester.ac.uk.

E Sydenham

London School of Hygiene and Tropical Medicine, Keppel Street, London WC1E 7HT, UK Emma.Sydenham@Lshtm.ac.uk

Competing interests: None.

\section{REFERENCES}

1. McClure R, Turner C, Peel N, et al. Population-based interventions for the prevention of fall-related injuries in older people. Cochrane Database Syst Rev 2005;(1):CD004441.

2. Gillespie LD, Gillespie WJ, Robertson MC, et al. Interventions for preventing falls in elderly people. Cochrane Database Syst Rev 2003;(4):CD000340.

3. Parker MJ, Gillespie WJ, Gillespie LD. Hip protectors for preventing hip fractures in older people. Cochrane Database Syst Rev 2005;(3):CD001255.

4. Cameron I, Murray GR, Gillespie LD, et al. Interventions for preventing falls in older people in residential care facilities and hospitals. [Protocol] Cochrane Database Syst Rev 2005;(3):CD005465.

5. Gillespie LD, Robertson MC, Gillespie WJ, et al. Interventions for preventing falls in older people living in the community. [Protocol] Cochrane Database Syst Rev 2008;(2):CD007146.

6. Lindqvist K, Timpka T, Schelp L. Evaluation of an inter-organizational prevention program against injuries among the elderly in a WHO Safe Community. Public Health 2001;115:308-16.

7. Kempton A, Van Beurden E, Sladden T, et al. Older people can stay on their feet: final results of a community-based falls prevention programme. Health Promot Int 2000;15:27-33.

8. Lin MR, Hwang HF, Want YW, et al. Communitybased Tai Chi and its effect on injurious falls, balance, gait, and fear of falling in older people. Phys Ther 2006;86:1189-201.

9. Poulstrup A, Jeune B. Prevention of fall injuries requiring hospital treatment among communitydwelling elderly. Eur J Public Health 2000;10:45-50.

10. Svanstrom L, Ader M, Schelp L, et al. Preventing femoral fractures among elderly: the community safety approach. Safety Sci 1996;21:239-46.

11. Ytterstad B. The Harstad injury prevention study: community based prevention of fall-fractures in the elderly evaluated means of a hospital based injury recording system in Norway. J Epidemiol Commun Health 1996;50:551-8.

12. WHO Collaborating Centre on Community Safety Promotion at the Karolinska Institute. The Safe Community Network (Monograph). Violence and Injury Prevention. Stockholm: World Health Organization, 1999 